\title{
You can achieve anything with a laser: ingenuity in the design of the impossible
}

\section{Ray Davies}

Ray Davies, "You can achieve anything with a laser: ingenuity in the design of the impossible," Proc. SPIE 9666, 11th Education and Training in Optics and Photonics Conference, 96661B (5 June 2009); doi: 10.1117/12.2207722

SPIE Event: Eleventh International Topical Meeting on Education and Training in Optics and Photonics, 2009, St. Asaph, United Kingdom 


\title{
You can achieve anything - with a Laser Ingenuity in the Design of the I mpossible Ray Davies Photonics Academy at OpTIC
}

\begin{abstract}
Abstralatthe area of Photonics Research as to what can be achieved with Low Power Photonics Sources, such as a Class 2 HeNe Laser, a Laser Diode, or an ultra high intensity LED, the Photonics Academy at OpTIC possesses a highly impressive array of functional Prototype Designs. Each of these visually attractive Prototype Designs illustrates the Ingenuity in Design that has been achieved by students, in the range of 15 - 25 years of age, who have been engaged in personal opportunities to Investigate the potential application of Photonics concepts to, and within, a whole range of highly Innovative outcomes, that are clear demonstrations of many students' individual Originality and Ingenuity in creating new ideas for the application of Low Power Photonics Concepts.

This Paper will highlight some of the highly Perceptive Prototype Design achievements of students in the application of Photonics principles, with these applications ranging from the Use of a Laser to identify the Letters of a Word in an ordinary book before translating them into Braille for a Visually Handicapped person, to the transmission of audio information over a distance; from a Book Page turning device for a paralysed person, to a pair of Laser Activated Mobile Feet; from a Mobile Guide Robot for a Blind person, to a five-Laser beam Combination Lock for a high Security application; from a Laser Birefringent Seismograph, to a Laser Speckle Activated Robotic Hand; and many, many more. All of the many functioning Prototype Design ideas that will be demonstrated have one characteristic that is common, namely, they are all designed with the intention to help improve the day-to-day experiences of other people, especially those who are impaired in some way. One of the most interesting challenges that can be presented to students is to apply Low Power Laser Photonics to help any visually impaired person within a whole range of activities, and several of the Prototype Designs will illustrate that particular type of student Ingenuity and Achievement via Perceptive Knowledge in Photonics.
\end{abstract}

Key Words: Achievement, Design, Data, Empirical, Imagination, Impossible, Information, Ingenuity, Insight, Investigative, Perceptive, Photon, Prototype, Op-Amp, Optoelectronics.

\section{Presentation}

1

The importance of demonstrating visually attractive Photonics Concepts to students.

The Following Photonics Concepts, and a smallselection of Prototype D esigns (all constructed by students), will be demonstrated:-

\subsubsection{PowerPoint demonstration of the effect of relatively changing the angle between two}

1.1 Twin Linear Ronché Gratings and Moiré Fringes. sets of Ronché Gratings.

1.1.2 PowerPoint demonstration of the effect of the relative vertical displacement of one Ronché Grating with respect to the other stationary Ronché Grating.

1.2 1.2.1 PowerPoint demonstration of the relative horizontal displacement of one Ronché Grating Twin Circular Ronché Gratings and Moiré Fringes.

with respect to the other stationary Ronché Grating.

1.2.2 The optical analogy of Young's Double Slit Interference Fringes.

1.3 Green Laser and $x-y$ cross Diffraction Gratings.

1.3.1 The 2-D images of multiple Laser Dot pattern with one $x-y$ cross Diffraction Grating.

1.3.2 The 2-D multiple Laser Dot pattern with two cross Diffraction Gratings - one rotating.

1.4 Laser Diode and Multimode Fibre Optic Laser Speckle.

1.4.1 Audio demonstration of the changing optical fibre Laser Speckle pattern.

1.4.2 Student Prototype Design for an innovative new Seismograph.

1.5 Automatic LED Oscillation Counting Device.

1.5.1 Counter for oscillations of a cantilever over 1 second.

1.5.2 Counter for oscillations of a cantilever over 4 seconds.

1.6 Five-Laser Beam Combination Lock.

1.6.1 Five-Laser Beam sequence $=x \times x \times 4$.

1.6.2 Alarm activated is 4 appears anywhere before final figure.

1.7 Laser and Fibre Optic Activated Robotic Hand.

1.7.1 LED Activation by Control Hand.

1.7.2 Opening and closing of Robotic Hand Fingers

Eleventh International Topical Meeting on Education and Training in Optics and

Photonics, edited by K. Alan Shore, Deb Kane, Proc. of SPIE Vol. 9666, 96661B

(C) 2009 SPIE, OSA, IEEE, ICO · doi: 10.1117/12.2207722 
1.8 Laser Diode Diffraction Activated Robotic Finger.

1.8.1 Motion of Control Finger.

1.8.2 Replication of Control Finger Movement in Robotic Finger.

1.9 Light Seeking Mobile Robots

1.10 Laser Activated Mobile Feet

1.11 Laser Speckle Eye-sight Test

1.12 Blind Person's Tea Cup Level Sensor

Additional Prototype Designs

Additional Prototype Designs may be viewed, by appointment, in visiting Unit 1, off The Street in OpTIC 3 Ingenuity in the Design of the I mpossible

In the Photonics Academy at OpTIC, students are always asked to select one response from the following sequence of three questions:-

3.1 Who likes doing things which are - easy ?

3.2 Who likes doing things which are - difficult ?

3.3 Who likes doing things which are - impossible ?

In the Photonics Academy at OpTIC, all the highly innovative Prototype Design outcomes materialize from a starting point that initially seems to be impossible. The impossible nature of the final outcome is always emphasized to the students, at the start of any Laser Photonics Design opportunity, and the ensuing challenge of attempting to achieve the impossible holds a great attraction for most students.

Impossible outcomes are purely outcomes that just remain in the future. When students are encouraged to focus their attention on to a specific Photonics concept, together with the "impossible" challenge of how that Photonics concept might be used for the benefit of Mankind, most students' imaginative thinking seems to be activated to a very perceptive level of original analysis. Young students really do appreciate an opportunity be become involved with the focused engagement of their imaginative thinking, when they realize that any Prototype Design outcome, which they may devise, also may be of benefit to Mankind.

The achievement of the impossible simply means drawing the "impossible" future towards the "possible" present. This transitional drawing of the "impossible" future into the "possible" present always requires the gathering of the empirical evidence, through very precise and specific investigative observations. Once the investigative observations have become evident, an accurate analysis of the implications of all of the empirically acquired evidence quickly leads any student towards a realization that the "impossible" future is not all that far into the future, and that it is possible for such a student to reach out to grasp the "impossible" future, and then begin to draw the impossible towards the possible.

The essential ingredients of Perceptive Knowledge are Insight, Imagination, and Ingenuity, all of which qualities are forward looking characteristics of a well motivated, and an inspired, student.

In the experience of the Photonics Academy at OpTIC, to focus the attention of a student on to a specific Photonics concept, and then to offer that student an opportunity to achieve an impossible outcome that will be of benefit to Mankind, really does inspire a student to want to learn, want to acquire perceptive knowledge, and want to apply that knowledge to a highly innovative new application of that Photonics concept.

The creation of imaginative Prototype Designs from within Photonics certainly does inspire students towards a desire for an acquisition of knowledge which is both perceptive, as well as useful.

\section{Conclusion}

Perceptive Empirical Design enables students to achieve quite outstanding and impressive changes within Science, through their personal I ngenuity of the Design of the I mpossible.

A student's sense of Personal Achievement in developing an innovative and valuable Prototype Design, through his, or her, Ingenuity of the Design of the I mpossible is of a very high quality factor. 